\title{
Acute Effects of Different Stretching Exercise Protocols on Some Anaerobic Motoric Tests
}

\section{Farklı Germe Egzersizi Protokollerinin Bazı Anaerobik Motorik Testler Üzerine Akut Etkileri}

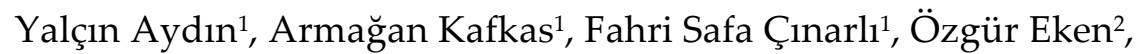 \\ Cem Kurt ${ }^{3}$, Muhammed Emin Kafkas ${ }^{1}$ \\ ${ }^{1}$ Department of Coaching Education, Faculty of Sport Sciences, İnönü University, Malatya, Turkey \\ ${ }^{2}$ Department of Physical Education and Sports Teaching, Faculty of Sport Sciences, İnönü University, Malatya, Turkey \\ ${ }^{3}$ Department of Coaching Education, Faculty of Sport Sciences, Trakya University, Edirne, Turkey
}

Y. Aydin

0000-0002-4634-244X

A. Kafkas

0000-0002-7276-0020

F. S. Çınarlı

0000-0002-7552-367X

Ö. Eken

0000-0002-5488-3158

C. Kurt

0000-0002-0254-5923

M. E. Kafkas

0000-0002-3962-6428

Geliş Tarihi/Date Received: 06.07.2018

Kabul Tarihi/Date Accepted: 05.10.2018

Yayın Tarihi/Published Online: 03.12.2018

Yazışma Adresi /

Corresponding Author:

Özgür Eken

İnönü Üniversitesi, Spor

Bilimleri Fakültesi, Malatya,

Türkiye

E-mail:

ozgureken86@gmail.com

(C2019 Türkiye Spor Hekimleri Derneği. Tüm hakları saklıdır.

\section{ABSTRACT}

Objective: In this study, it was aimed to investigate the acute effects of different stretching exercise protocols on some anaerobic motoric tests.

Material and Methods: The sample group of this study consists of 15 male (age: $21.8 \pm 1.4$ years, stature: $1.77 \pm 0.32 \mathrm{~m}$, body mass: $69.1 \pm 6.7 \mathrm{~kg}$, body mass index (BMI) $21.9 \pm 2.0 \mathrm{~kg} / \mathrm{m}^{2}$, body fat ratio (BFR) $10.9 \pm 4.0 \%$ ) volunteers who were engaged in regular exercise for at least three years. Volunteers performed five different stretching exercise protocols on non-consecutive days. Stretching exercise protocols were determined as follows: light jogging for only 5 mins (NS), light jogging and static stretching exercise (SS), light jogging and dynamic stretching exercise (DS), light jogging and static stretching exercise + dynamic stretching exercise (SDS), light jogging and dynamic stretching exercise + static stretching exercise (DSS). "Repeated measures ANOVA" test was used to determine the effect of different stretching exercise protocols on vertical jumping, agility, anaerobic power, mean power and linear running scores.

Results: Different stretching protocols did not make a statistically significant effect on vertical jumping, anaerobic power, mean power and agility test results $(p>0.05)$. Participants' linear running test results for 10,20 and $30 \mathrm{~m}$ revealed significant differences with respect to stretching protocols (respectively $p<0.001, p<0.001$ ve $\mathrm{p}<0.01$ ).

Conclusion: The results of this study revealed that linear running performance figures were observed to be highest after dynamic stretching exercise. Dynamic stretching exercise protocols are recommended to trainers and athletes in order to reach better performance in $10 \mathrm{~m}, 20 \mathrm{~m}$ and $30 \mathrm{~m}$ sprints.

Keywords: Vertical jumping, linear running, agility, stretching exercises, anaerobic power

\section{ÖZ}

Amaç: Bu çalışmada farklı germe egzersizi protokollerinin bazı anaerobik motorik testler üzerine akut etkisinin incelenmesi amaçlandı.

Gereç ve Yöntemler: Araştırmaya en az üç yıldır düzenli spor yapan 15 erkek denek, (yaş: $21.8 \pm 1.4$ yıl, boy $1.77 \pm 0.32 \mathrm{~m}$, vücut ağırlığı: $69.1 \pm 6.7 \mathrm{~kg}$, vücut kütle indeksi (VKI) $21.9 \pm 2.0 \mathrm{~kg} / \mathrm{m}^{2}$ ve vücut yağ oranları (VYO) $10.9 \pm 4.0 \%$ ) gönüllü olarak katıldı. 
Gönülülere birbirini izlemeyen günlerde beş farklı germe egzersizi protokolü uygulandı. Germe egzersizi protokolleri olarak $5 \mathrm{dk}$ hafif tempo koşu (GUE), $5 \mathrm{dk}$ hafif tempo koşu ve statik germe egzersizi (SG), $5 \mathrm{dk}$ hafif tempo koşu ve dinamik germe egzersizi (DG), $5 \mathrm{dk}$ hafif tempo koşu ve statik germe egzersizi + dinamik germe egzersizi (SDG), $5 \mathrm{dk}$ hafif tempo koşu ve dinamik germe egzersizi + statik germe egzersizi (DSG) uygulandı. Farklı germe egzersizi protokolleri arasındaki anlamlılık sınaması için tekrarlayan ölçümlü (repeated) ANOVA kullanıldı.

Bulgular: Farklı germe egzersizi protokollerinin dikey sıçrama, zirve güç, ortalama güç, çeviklik performansı sonuçları üzerinde istatistiksel olarak anlamlı bir etkisi olmadığı saptandı $(p>0.05)$. Germe egzersizi protokollerine göre, katılımcıların $10 \mathrm{~m}, 20 \mathrm{~m}$ ve $30 \mathrm{~m}$ doğrusal koşu testi sonuçları istatistiksel olarak farklı (sırasıyla $p<0.001, p<0.001$ ve $\mathrm{p}<0.01$ ) anlamlı bulundu.

Sonuç: Araştırma sonucunda elde edilen bulgulara göre; farklı germe egzersizi protokollerinin ilgili motor performans parametreleri açısından farklı etkilere sahip olduğu görüldü. Antrenör ve sporculara $10 \mathrm{~m}, 20 \mathrm{~m}$ ve $30 \mathrm{~m}$ doğrusal koşu performansından daha çok verim alabilmeleri amacıyla öncesinde dinamik germe egzersizi uygulamaları önerilebilir.

Anahtar Sözcükler: Dikey sıçrama, doğrusal koşu, çeviklik, germe egzersizi, anaerobik güç

Available at: http://journalofsportsmedicine.org and http://dx.doi.org/10.5152/tjsm.2019.121

Cite this article as: Aydin Y, Kafkas, A, Cinarli FS, et al. Acute effect of different stretching exercise protocols on some anaerobic motoric tests. Turk J Sports Med. 2019;54(2):99-107.

\section{GíRis}

Pek çok sporcu, yaralanmaların önlenmesi ve esneklik artışı ile performanslarının arttırılması için fiziksel aktivite öncesi ısınma eyleminin bir parçası olarak germe egzersizleri yapmaktadır (1). Isınmadaki ilk hedef, özellikle kasların iç ısısını arttırmaktır (2). Böylelikle egzersiz sırasında kas glikolizi ve yüksek enerjili fosfat yıkımı verimliliğinin artabileceği belirtilmiştir. Anaerobik metabolizma bağımlılığı artışı sonraki egzersiz performansını belirgin şekilde etkileyebilmektedir. Adenozin trifosfat tüketimi ve üretimi, kas kasılma hızı ve oksijen alım kinetiklerini etkileyerek kas fonksiyonlarını geliştirebilir (3). Kas ısısındaki artışın, kas metabolizması ve kas liflerinin iletim hızındaki artışa eşlik ettiği ve sonuç olarak $\mathrm{VO}_{2}$ kinetiğinin önceki kasılma aktivitesini izleyen kas kasılabilirliğinde pozitif değişime neden olduğu bildirilmektedir. Ayrıca kas ısısındaki artışın, kas ve eklemlerin viskoz direncinde düşüş yoluyla performansı etkileyebileceği, bununla birlikte aktif ısınmayı izleyen fizyolojik ve performans değişikliklerinin asıl nedeninin kalıcı metabolik asidemi (asit artışı) olabileceği öne sürülmüştür $(4,5)$.

Literatürde farklı germe egzersizi protokolleri yer almaktadır: statik, dinamik, kombine ve balistik germeler, proprioseptif nöromüsküler fasilitasyon (PNF) ve spor dalına özgü germe egzersizi yöntemleri gibi. Bu germe egzersizi protokollerinden biri olan statik germe egzersizi; hareket aralığının sonuna kadar eklemi 15 ila 60 saniye boyunca uzatılmış konumda tutmayı içermektedir (6). Statik germe egzersizi, kas gevşemesini ve dolayısıyla gerilmeyi ve eklem hareket açıklığını destekleyen ters miyotatik refleksten yararlanır. Yavaş ve kontrollü hareket, gerilmenin diğer gerilme biçimlerine klyasla daha az yaralanma riskiyle güvenli bir şekilde gerçekleştirilmesini sağlar (7). Son zamanlarda birçok çalışma, orta seviyede statik germe egzersizinin (kas grubuna göre 15-30 saniye) kısa süreli kas kuvvetini etkilemediğini, orta ve yüksek seviyede yapılan statik germe egzersizinin ise (30-60-90 saniye) sıçrama yüksekliğini, hızı ve gücü azalttığını bildirmektedir (8-12).

Statik germe egzersizinin performans üzerindeki negatif etkisini ortaya koyan çalışmalar antrenör, sporcu ve spor bilimcileri farklı germe egzersizi protokollerine yönlendirmiştir. Slklıkla tercih edilen germe egzersizi uygulamalarından biri dinamik germe egzersizidir ve temelde sıçrama, atlama, alt ve üst ekstremiteye yönelik spesifik egzersizler yer alır (13). Dinamik germe egzersizinin sürat (14), çeviklik, uzağa sağlık topu fırlatma, beş adım sıçrama (15) ve dikey sıçrama (16) performansını arttırdığı gözlemlenmiştir. Buna neden olarak sportif aktivite öncesinde dinamik germe egzersizi gibi düşük yoğunluktan yüksek yoğunluğa doğru yapılan istemli kasılmaların, sinir-kas aktivasyonunu aktif hale getirerek güç ve performansı arttırması gösterilmiştir $(17,18)$. 
Germe egzersizinin performans parametreleri üzerine etkilerinin araştırıldığı çalıșmalar incelendiğinde, uygulanan beș farklı germe egzersiz protokolünün (GUE, SG, DG, SG+DG, DG+SG) dikey sıçrama, 10-20-30 m doğrusal koșu ve çeviklik performansına akut etkisini ölçen herhangi bir çalışmaya rastlanmadı. Bu çalışmanın amacı farklı germe egzersizi protokollerinin bazı anaerobik motorik testler üzerindeki akut etkisinin belirlenmesidir. Bu amaçla araştırmanın hipotezleri; (1) anaerobik performans testlerinin farkl germe egzersizi protokollerinden etkileneceği ve (2) dikey sıçrama, 10-20-30 m doğrusal koşu ve çeviklik açısından dinamik germenin daha etkili olacağı şeklindedir.

\section{GEREÇ ve YÖNTEMLER}

\section{Katılımclar}

Araştırmaya Spor Bilimleri Fakültesinde okuyan, yaşları 21.8 \pm 1.4 yıl olan 15 erkek gönüllü katıldı (Fiziksel özellikler için bkz. Tablo 1). Katılımcılar testlerin uygulanması konusunda herhangi bir sağlık problemlerinin olmaması, rızalarının alınmış olması, testler süresince gönüllü olmaları ve düzenli katılım göstermeleri dâhil edilme kriterleri olarak belirlendi. Çıkarılma kriterleri ise çalışma süresince herhangi bir sağllk problemiyle karşılaşılması, ölçümlere katılımda düzensizlik, performansın optimum düzeyde sergilenmemesi ve özensiz davranışlar olarak belirlendi. Tüm testler ve antrenman uygulamaları diürnal ritim etkisinden kaçınmak için günün aynı saatinde (9:00-11:00) yapıldı. Araştırma yerel klinik araştırmalar etik kurulu onayı alınarak uyguland.

\section{Araştırmanın Deneysel Tasarımı}

Çalışmaya katılan sporcuların antropometrik ölçümleri yapıldı. Ölçümler İnönü Üniversitesi Spor Bilimleri Fakültesi Spor Salonunda gerçekleştirildi. Tüm gönüllülere çalışma içeriğine ilişkin bilgiler önceden uygulamalı olarak tüm ayrıntılarıyla anlatıldı. Testlerin şekli, konusu, yeri ve zamanı hakkında gönüllülere gerekli bilgiler verildi. İlk ısınmadan (5 dk orta şiddetli aerobik koşu-jogging) sonraki evrelerde germe uzman gözetiminde yapıldı. Testlerden 24 saat önce ağır egzersiz yapmamaları, alkol, kafein ve ergojenik yardımcı kapsamına giren maddeleri kullanmamalarına ilişkin bilgilendirmeler yapıldı. Her bir germe egzersizi protokolü, $5 \mathrm{dk}$ düşük tempoda (jogging) aerobik koşu ile başladı. Gönüllüler, koşu tamamlandıktan sonra birinci ısınma uygulaması dişındaki uygulamalardan sonra, motorik testleri gerçekleștirdi. Birinci ısınma uygulaması dışındaki her bir germe egzersizi sonrasında sırasıyla dikey sıçrama, Tline çeviklik (19), doğrusal koşu (10-20-30m) test performansları ölçüldü.

\section{Anaerobik Güç}

Gönüllülerin zirve ve ortalama anaerobik güçleri, sıçrama mesafesi, vücut ağırlığı ve boy uzunluğu verilerinden yararlanılarak Johnson \& Bahamonde (20) formülü ile hesaplandı:

Zirve güç $(\mathrm{W})=[78.6 \times \mathrm{Ds}(\mathrm{cm})]+[60.3 \mathrm{x} \mathrm{Va}(\mathrm{kg})]$ - $[15.3 \mathrm{x}$ boy $(\mathrm{cm})]-1308$;

Ortalama güç $(\mathrm{W})=[43.8 \times \mathrm{Ds}(\mathrm{cm})]+[32.7 \mathrm{x} \mathrm{Va}(\mathrm{kg})]$ - $[16.8 \mathrm{x}$ boy $(\mathrm{cm})]+431$.

Burada Ds, dikey sıçrama; Va, vücut ağırlığıdır.

\section{Germe Egzersizi Protokolleri}

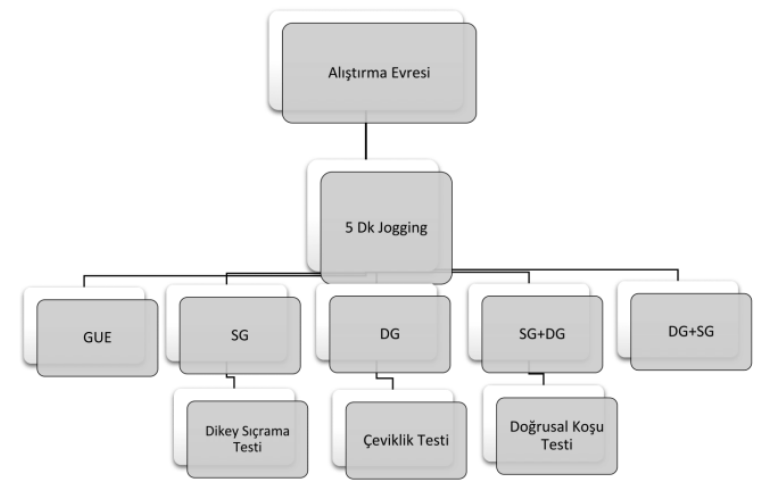

Şekil 1. Deneysel tasarım

\section{Germe Egzersizi Uygulanmayan Evre (GUE)}

Bu evre 5 dakika düşük tempoda aerobik koşudan oluşur; 5 dakikalık koşu sonrası başka bir egzersiz uygulaması yapılmadan katılımcıların; 
dikey sıçrama, doğrusal koşu (10m, 20m, 30 m) ve çeviklik performansları ölçüldü. Üük tempo koşu sırasında egzersizin şiddetini belirlemek için rastgele seçilen 15 kişilik gruptaki dört kişiye kalp atım monitörü ve göğüs bandı takılarak çalışmaya katılan deneklerin kalp atım hızları Karvonen formülü kullanılarak ısınma yoğunluğu gönüllülerin \%30-40'ı olacak șekilde belirlendi (21). Bu şekilde hem isınmanın yoğunluğuna bakılmış, hem de çalışmaya katılan gönüllüler arasındaki ısınma farklılığı ortadan kaldırıldı.

\section{Statik Germe Egzersizi (SG)}

$\mathrm{Bu}$ evrede gerekli ısınma (5 dk düşük tempoda aerobik koşu) yapıldıktan ve vücut dinlenik hale getirildikten sonra, alt ve üst ekstremitelere uygulanan sekiz statik germe egzersizi ile evre devam edilmektedir. Statik germe egzersizleri yavaş bir germeden ağrı eşiğindeki gergin bir duyarlılık seviyesine kadar iki kez 30 s ve tekrarlar arası $15 \mathrm{~s}$ arayla uygulandı. Statik germe egzersizi, sağ ve sol ekstremitelere ayrı ayrı uygulandı (22). Latissimus dorsi (sırt), pectoralis major (göğüs), trapezius (boyun), rectus abdominis (karın), gluteus maximus (kalça), quadriceps (bacak ön), hamstring (bacak arka), gastrocnemius (baldır) kas gruplarına yönelikti. Her bir kas için statik germe egzersizi uygulandıktan sonra aerobik ve anaerobik motorik testlerin uygulanmasına geçildi.

\section{Dinamik Germe Egzersizi (DG)}

Bu evrede gerekli ısınma (5 dk düşük tempoda aerobik koşu) yapıldıktan ve vücut dinlenik hale getirildikten sonra, sekiz farklı dinamik germe egzersizi ile evreye devam edildi. Deneklere her bir germe egzersizi, iki kez $30 \mathrm{~s}$ ve tekrarlar arası $15 \mathrm{~s}$ dinlenme aralığı olacak şekilde, $15 \mathrm{~m}$ boyunca ve gittikçe artan tempo düzeyinde uygulandı ve aynı egzersiz başlama çizgisine geri dönene kadar yinelendi. Hareketlerin istenilen şekilde ve doğru yapılması konusunda deneklere gereken bilgilendirme yapıldı (23). Uygulanacak dinamik germeler; yüksek kalça çekişi (high glute pull), ileri hamle yürüyüşü (walking lung), hafif yüksek diz çekişi (light high knees), yüksek diz çekişi (high knee pull), düz ayak vurma (straight leg kick), carioka, skip A (atlama), B skip (atlama), dinamik germeler uygulandıktan sonra aerobik ve anaerobik motorik testlerin uygulanmasına geçildi.

\section{Statik + Dinamik Germe Egzersizi $(S G+D G)$}

$\mathrm{Bu}$ evrede gerekli ısınma (5 dk düşük tempoda aerobik koşu) yapıldıktan ve vücut dinlenik hale getirildikten sonra, uygulanan sekiz statik ve sekiz dinamik germe egzersizi ile evreye devam edildi. Statik ve dinamik germe uygulamaları, bir kez $30 \mathrm{~s}$ ve tekrarlar arası $15 \mathrm{~s}$ arayla uygulandı.

\section{Dinamik + Statik Germe Egzersizi $(D G+S G)$}

$\mathrm{Bu}$ evrede gerekli ısınma ( $5 \mathrm{dk}$ düşük tempoda aerobik koşu) yapıldıktan ve vücut dinlenik hale getirildikten sonra, uygulanan sekiz dinamik ve sekiz statik germe egzersizi ile evreye devam edildi. Statik ve dinamik germe egzersizleri, bir kez $30 \mathrm{~s}$ ve tekrarlar arası $15 \mathrm{~s}$ arayla uygulandı.

\section{İstatistiksel Analiz}

Farklı germe egzersizi protokolleri arasındaki anlamlılık sınaması için tekrarlı ölçümler varyans analizi kullanıldı. Küresellik varsayımı Mauchly's Küresellik testi ile değerlendirildi.

Verilerin küresellik varsayımını karşıladığı durumlarda "Sphericity Assumed"; bu varsayımın karşılanmadığı durumlarda "Greenhouse Geisser's" testleri kullanıldı. Farklı germe egzersiz protokollerinin etki büyüklükleri "eta kare" $\left(\eta^{2}\right)$ değerleri ile açılklandı. Verilerin analizinde SPSS 23.0 istatistik programı (SPSS Inc, Chicago, IL) kullanıldı ve istatistiksel anlamlılık düzeyi olarak $\mathrm{p}<0.05$ kabul edildi. Araştırma bulguları aritmetik ortalama \pm standart sapma $(\mathrm{X} \pm \mathrm{SS})$ olarak gösterildi. 
Tablo 1. Germe egzersizi protokolleri

\begin{tabular}{|c|c|c|c|c|}
\hline GUE & SG & DG & SG+DG & DG+SG \\
\hline \multirow[t]{8}{*}{$\begin{array}{l}5 \mathrm{dk} \text { düşük tempo } \\
\text { aerobik koșu }\end{array}$} & $\begin{array}{l}\text { Latissimus dorsi } \\
\text { (sirt) kas grubu }\end{array}$ & $\begin{array}{l}\text { Yüksek kalça çekişi } \\
\text { (High glute pull) }\end{array}$ & $\begin{array}{l}\text { Latissimus dorsi } \\
\text { (sırt) kas grubu + } \\
\text { Yüksek kalça çekişi } \\
\text { (High glute pull) }\end{array}$ & $\begin{array}{l}\text { Yüksek kalça çekiși } \\
\text { (High glute pull) + } \\
\text { Latissimus dorsi } \\
\text { (sırt) kas grubu }\end{array}$ \\
\hline & $\begin{array}{l}\text { Pectoralis major } \\
\text { (göğüs) kas grubu }\end{array}$ & $\begin{array}{l}\text { İleri hamle } \\
\text { yürüyüşü (Walking } \\
\text { lung) }\end{array}$ & $\begin{array}{l}\text { Pectoralis major } \\
\text { (göğüs) kas grubu + } \\
\text { İleri hamle } \\
\text { yürüyüşü (Walking } \\
\text { lung) }\end{array}$ & $\begin{array}{l}\text { İleri Hamle } \\
\text { Yürüyüşü } \\
\text { (Walkingl)+ } \\
\text { Pectoralis major } \\
\text { (göğüs) kas grubu }\end{array}$ \\
\hline & $\begin{array}{l}\text { Trapezius (boyun) } \\
\text { kas grubu }\end{array}$ & $\begin{array}{l}\text { Hafif yüksek diz } \\
\text { çekişi (Light high } \\
\text { knees) }\end{array}$ & $\begin{array}{l}\text { Trapezius (boyun) } \\
\text { kas grubu+ Hafif } \\
\text { yüksek diz çekişi } \\
\text { (Light high knees) }\end{array}$ & $\begin{array}{l}\text { Hafif yüksek diz } \\
\text { çekişi (Light high } \\
\text { knees) + Trapezius } \\
\text { (boyun) kas grubu }\end{array}$ \\
\hline & $\begin{array}{l}\text { Abdominis (karın) } \\
\text { kas grubu }\end{array}$ & $\begin{array}{l}\text { Yüksek diz çekişi } \\
\text { (High knee pull) }\end{array}$ & $\begin{array}{l}\text { Abdominis (karın) } \\
\text { kas grubu + Yüksek } \\
\text { diz çekişi (High knee } \\
\text { pull) }\end{array}$ & $\begin{array}{l}\text { Yüksek diz çekişi } \\
\text { (High knee pull) + } \\
\text { Abdominis (karın) } \\
\text { kas grubu }\end{array}$ \\
\hline & $\begin{array}{l}\text { Gluteus maximus } \\
\text { (kalça) kas grubu }\end{array}$ & $\begin{array}{l}\text { Düz ayak vurma } \\
\text { (Straight leg kick) }\end{array}$ & $\begin{array}{l}\text { Gluteus maximus } \\
\text { (kalça) kas grubu + } \\
\text { Düz ayak vurma } \\
\text { (Straight leg kick) }\end{array}$ & $\begin{array}{l}\text { Düz ayak vurma } \\
\text { (Straight leg kick) + } \\
\text { Gluteus maximus } \\
\text { (kalça) kas grubu }\end{array}$ \\
\hline & $\begin{array}{l}\text { Quadriceps (bacak } \\
\text { ön) kas grubu }\end{array}$ & Karioka & $\begin{array}{l}\text { Quadriceps (bacak } \\
\text { ön) kas grubu + } \\
\text { Karioka }\end{array}$ & $\begin{array}{l}\text { Karioka + } \\
\text { Quadriceps (bacak } \\
\text { ön) kas grubu }\end{array}$ \\
\hline & $\begin{array}{l}\text { Hamstring (bacak } \\
\text { arka) kas grubu }\end{array}$ & Skip A (atlama) & $\begin{array}{l}\text { Hamstring (bacak } \\
\text { arka) kas grubu + } \\
\text { Skip A (atlama) }\end{array}$ & $\begin{array}{l}\text { Skip A (atlama) + } \\
\text { Hamstring (bacak } \\
\text { arka) kas grubu }\end{array}$ \\
\hline & $\begin{array}{l}\text { Calf (baldır) kas } \\
\text { grubu }\end{array}$ & Skip B (atlama) & $\begin{array}{l}\text { Calf (baldır) kas } \\
\text { grubu + Skip B } \\
\text { (atlama) }\end{array}$ & $\begin{array}{l}\text { Skip B (atlama) + } \\
\text { Calf (baldır) kas } \\
\text { grubu }\end{array}$ \\
\hline
\end{tabular}

GUE: Germe uygulanmayan evre, SG: Statik germe, DG: Dinamik germe, SG+DG: Statik germe+Dinamik germe, DG+SG: Dinamik germe+Statik germe

\section{BULGULAR}

Tablo 2'de çalışmaya katılan gönüllülerin fiziksel özellikleri olarak yaşları, boyları, vücut ağırlıkları,
VKI'leri, VYO'ları ve YVA'ları minimum-maksimum, ort. $(\mathrm{X}) \pm$ SS olarak verilmektedir.

Tablo 2. Katılımcıların fiziksel değerleri

\begin{tabular}{lccc}
\hline Parametreler & $\mathbf{N}$ & Minimum-Maksimum & X \pm SS \\
\hline Yaş (yıl) & 15 & $19.0-24.0$ & $21.8 \pm 1.4$ \\
Boy $(\mathrm{m})$ & 15 & $1.73-1.84$ & $1.77 \pm 0.32$ \\
VA $(\mathrm{kg})$ & 15 & $58.8-81.7$ & $68.4 \pm 6.8$ \\
VKİ $\left(\mathrm{kg} / \mathrm{m}^{2}\right)$ & 15 & $19.2-25.8$ & $21.8 \pm 2.0$ \\
VYO $(\%)$ & 15 & $6.2-18.0$ & $10.9 \pm 4.0$ \\
YVA $(\mathrm{kg})$ & 15 & $55.0-71.3$ & $60.8 \pm 5.1$ \\
DKAS $(\mathrm{n})$ & 15 & $54-70$ & $63.7 \pm 4.5$ \\
\hline
\end{tabular}

VA: vücut ağırlı̆̆ı; VKİ: vücut kütle indeksi; VYO: vücut yağ oranı; YVA: yağsız vücut ağırlığı; DKAS: dinlenik kalp atım sayısı 
Tablo 3'de çalışmaya katılan gönüllülerin germe egzersizi protokollerine göre performans değerleri verilmektedir. Farklı protokollerin dikey sıçrama performansı ( $p>0.05)$, zirve güç $(p>0.05)$, ortalama güç $(p>0.05)$ ve çeviklik değerleri $(p>0.05)$ üzerinde istatistiksel anlamlı bir etkiye sahip olmadığı saptandı.

Tablo 3. Katılımcıların germe egzersizi protokollerine göre dikey sıçrama, zirve güç, ortalama güç ve çeviklik değerlerinin karșılaștırılması

\begin{tabular}{lcccc}
\hline Protokol & $\begin{array}{c}\text { Dikey sıçrama } \\
(\mathrm{cm})\end{array}$ & $\begin{array}{c}\text { Zirve güç } \\
\text { (W) }\end{array}$ & $\begin{array}{c}\text { Ortalama güç } \\
\text { (W) }\end{array}$ & $\begin{array}{c}\text { Çeviklik } \\
(\mathrm{s})\end{array}$ \\
\hline GUE & $35.6 \pm 4.2$ & $4211 \pm 565$ & $1251 \pm 303$ & $10.68 \pm 0.54$ \\
SG & $34.8 \pm 4.6$ & $4148 \pm 578$ & $1216 \pm 315$ & $10.80 \pm 0.54$ \\
DG & $36.2 \pm 5.9$ & $4259 \pm 666$ & $1278 \pm 359$ & $10.64 \pm 0.67$ \\
SG+DG & $35.3 \pm 4.0$ & $4258 \pm 666$ & $1241 \pm 227$ & $10.73 \pm 0.60$ \\
DG+SG & $35.0 \pm 5.2$ & $4163 \pm 530$ & $1225 \pm 288$ & $10.65 \pm 0.52$ \\
\hline
\end{tabular}

Değerler Ort. \pm SS olarak; GUE: Germe uygulanmayan evre; SG: Statik germe; DG: Dinamik germe; SG+DG: Statik germe+Dinamik germe; DG+SG: Dinamik germe+Statik germe

Tablo 4'de farklı germe egzersizi protokollerinin $10 \mathrm{~m}$ koşu değerleri üzerinde istatistiksel anlamlı bir etkiye sahip olduğu görülmektedir $(\mathrm{p}<0.001)$. Katılımcıların $10 \mathrm{~m}$ doğrusal koşu performansı değerleri incelendiğinde protokoller arasında; $S G+D G$ ile GUE, DG+SG ile GUE, SG+DG ile SG, DG+SG ile SG, SG+DG ile DG ve son olarak DG+SG ile DG, DG ile GUE egzersizleri egzersizleri arasında istatistiksel olarak anlamlı farklılık olduğu saptandı $(\mathrm{p}<0.05)$.

Tablo 4. Katılımcıların germe egzersizi protokolleri açısından doğrusal koşu performansı değerlerinin karşılaştırılması

\begin{tabular}{lccc}
\hline Protokol & $\mathbf{1 0} \mathbf{~ m}(\mathrm{s})$ & $\mathbf{2 0} \mathbf{~ m}(\mathrm{s})$ & $\mathbf{3 0 ~} \mathrm{m}(\mathrm{s})$ \\
\hline GUE & $1.77 \pm 0.08$ & $3.10 \pm 0.15$ & $4.44 \pm 0.27$ \\
SG & $1.72 \pm 0.10$ & $3.08 \pm 0.15$ & $4.40 \pm 0.24$ \\
DG & $1.62 \pm 0.07^{*}$ & $2.95 \pm 0.14^{*}$ & $4.22 \pm 0.19^{* *}$ \\
SG+DG & $1.64 \pm 0.08^{*}$ & $2.99 \pm 0.14^{*}$ & $4.32 \pm 0.21^{* * *}$ \\
DG+SG & $1.63 \pm 0.09^{*}$ & $2.99 \pm 0.15^{*}$ & $4.28 \pm 0.23^{* *}$ \\
\hline
\end{tabular}

Değerler Ort SS șeklinde; GUE: Germe uygulanmayan evre; SG: Statik germe; DG: Dinamik germe; SG+DG: Statik germe+Dinamik germe; DG+SG: Dinamik germe+ Statik germe; ${ }^{*}=\mathrm{p}<0.001 ;{ }^{* *}=\mathrm{p}<0.01 ;^{* * *}=\mathrm{p}<0.05$

Farklı germe egzersizi protokollerinin $20 \mathrm{~m}$ değerleri üzerinde istatistiksel olarak anlamlı bir etkiye sahip olduğu belirlendi $(\mathrm{p}<0.001)$. Protokoller arasında; $20 \mathrm{~m}$ değerleri açısından, SG+DG ile SG, SG+DG ile DG ve son olarak DG+SG ile DG egzersizleri arasinda istatistiksel olarak anlamlı farklılık gözlendi $(\mathrm{p}<0.05)$. Bunun yanı sira, farklı germe egzersizi protokollerinin $20 \mathrm{~m}$ doğrusal koşu performansı üzerine etkisi \%35.5 olarak hesaplandı.

Farklı germe egzersizi protokollerinin $30 \mathrm{~m}$ değerleri üzerinde istatistiksel olarak anlamlı bir etkiye sahip olduğu saptandı $(\mathrm{p}<0.01)$. Protokoller arasında; $30 \mathrm{~m}$ değerleri açısından, SG+DG ile DG ve DG+SG ile DG egzersizleri arasında istatistiksel olarak anlaml farklılık belirlendi $(\mathrm{p}<0.05)$. Bunun yanı sıra, farklı 
germe egzersizi protokollerinin $30 \mathrm{~m}$ doğrusal koşu performansı üzerine etkisi \%26.5 olarak bulundu.

\section{TARTIŞMA}

Araştırmada beș farklı germe egzersizi protokolünün (GUE, SG, DG, SG+DG, DG+SG) bazı anaerobik motorik testler üzerine akut etkisi incelendi. Germe egzersizi protokollerinin etkisini incelemek amacıyla dikey sıçrama, çeviklik ve 10-20-30 m doğrusal koşu testleri seçildi.

Gönüllülerin germe egzersizi protokollerinin dikey sıçrama performans değerleri üzerinde istatistiksel olarak anlaml bir etkiye sahip olmadığı saptandı ( $p>0.05)$. Literatürde germe egzersizi protokolleri sonrası dikey sıçrama performansının değerlendirildiği çalışmalarda; Little ve Williams'ın futbolcularda egzersiz öncesi uygulanan farklı germe egzersizi protokollerinin dikey sıçrama, $10 \mathrm{~m}, 20 \mathrm{~m}$ sprint ve çeviklik gibi futbolcular için önemli olan motor kapasitelerine etkisini incelemişler ve sonuç olarak; dinamik germe egzersizleri sonrası ölçümlerde ilgili performans parametreleri üzerinde pozitif yönde istatistiksel olarak anlamlı bir artış gözlemlemişlerdir (24). Haghshenas ve ark. (25) ise farkl germe protokollerinin voleybolcularda dikey sıçrama performansı üzerindeki akut etkiyi incelemeyi amaçlamışlardır. Rastlantısal olarak tasarlanmış farklı germe protokollerinde katılımcllar; germe olmaksızın, statik germe, dinamik germe ve kombine edilmiş germeden oluşan protokollere uyuglamışlardır. Sonuç olarak; dinamik germe $(49.1 \pm 7.0 \mathrm{~cm})$ ve statik $(47.4 \pm 7.1 \mathrm{~cm})$ germe karşılaştırıldığında anaerobik güçte dinamik germe lehine belirgin bir artış gözlenmiştir (25).

Franco ve ark. (26) farklı germe egzersizlerinin geleneksel Wingate testi (WT) performansina olan akut etkilerini incelemeyi amaçlamıştır. On beş erkek katılımcı beş Wingate testinden birini alıştırma esnasında ve diğer dördünü; germe olmayan evre, statik germe (SG), dinamik germe (DG) ve propriyoseptif nöromüsküler fasilitasyon (PNF) germe olarak gerçekleştirmişlerdir. PNF germe $(7.3 \pm 0.9 \mathrm{~W} / \mathrm{kg})$ dinamik germe $(7.7 \pm 0.9$
$\mathrm{W} / \mathrm{kg}$ ) ile karşılaştırıldığında, ortalama gücün istatistiksel olarak düşük olduğu belirlenmiştir $(p<0.05)$. Tüm germe egzersizleri, germe olmayan evre ile kıyaslandığında, zirve güç çıkışına ulaşmak için tutarlı bir zaman artışı gözlemlenmiştir (26). Kendall (27) statik ve dinamik germe egzersizlerinin anaerobik güç üzerine etkisini araştırmak için, Wingate anaerobik güç testi sonuçlarını farklı germe egzersizi protokolü durumunda ve germe egzersizi olmaksızın elde edilen veriler ile karşılaştırmış ve sonucunda, germenin zirve güç değerlerinde anlamlı değişime sebep olduğunu ve bu değerin dinamik germe egzersizleri yapıldığında daha yüksek olduğunu saptamıștır.

Dinamik germe egzersizi sonrası anaerobik güç, dikey sıçrama, kuvvet, sürat gibi parametrelerin statik germeye göre daha iyi olması Bishop'un (4) "aktif dinamik isınma egzersizi sinir iletimini arttırır, hız-kuvvet ilişkisini geliştirir, çeviklik performansını geliştirir, glikojenoliz ve glikolizi arttırır" ifadesini desteklemektedir.

Katılımcların germe egzersizi protokolleri açısından çeviklik performansları incelendiğinde istatistiksel olarak anlamlı bir etki belirlenmedi ( $p>0.05)$. Little ve Williams (24) İngiltere Premier Liginden 18 profesyonel futbolcunda ısınma sırasında farklı germe protokollerinin yüksek hızlı motor kapasiteleri üzerindeki etkilerini ölçmüştür. Bu çalışma sonucunda, statik germe egzersizlerinin çeviklik performansında bir değişime neden olmadığı saptanmıştır (24). McMillan ve ark. (15) yaş ortalamaları $20.2 \pm 1.2$ yıl, boyları $182.4 \pm 6.6 \mathrm{~cm}$ ve vücut ağırlığı $88.8 \pm 9.0 \mathrm{~kg}$ olan 16 erkek ve ortalama yaşları $20.4 \pm 1.5$ yıl, boyları $167.1 \pm 6.7$ $\mathrm{cm}$ ve vücut ağırlıklkları $64.0 \pm 7.8 \mathrm{~kg}$ olan 14 kadın sporcunun dinamik ve statik germe sonrası güç ve çevikliklerini değerlendirmişler; statik germe egzersizlerinin çeviklik performansını değiştirmediğini bildirmişlerdir (15).

Chatzopoulos ve ark. (28) çalışmalarında 31 kadın lise sporcusunda (yaş $17.3 \pm 0.5$ yıl).üç farklı germe protokolünün akut etkilerini denge, çeviklik, reaksiyon zamanı ve üst uzuvların hareket süresi aracılığında karşılaştırmayı amaçlamışlardır. Dinamik germe ile kıyasla, 
statik germe protokolü denge, çeviklik ve hareket süresinde önemli ölçüde daha kötü performansa yol açmıştır. Amiri-Khorasani ve ark. (29) çalışmalarında, egzersiz öncesi ısınmada statik, dinamik ve statik ve dinamik germe kombinasyonunun 19 profesyonel futbolcunun (yaş $22.5 \pm 2.5$ yll, boy $1.79 \pm 0.03 \mathrm{~m}$, vücut kütlesi $74.8 \pm 10.9 \mathrm{~kg}$ ) Illinois agility testleri (IAT) üzerindeki etkilerini incelemeyi amaçlamışlardır. Çalışma sonucunda, statik germenin, dinamik germeyle kombine edilmiş ısınma sonrası çeviklik performansını geliştirmediği belirlenmiştir (29). Sonuç fizyolojik açıdan, kas tendon sistemindeki uzunluk artışı ve kas gerginliğindeki azalma ile $(30,31)$, statik germenin bir sonucu olarak kasın tendonundaki biyomekaniksel değişim sonucu kasın daha esnek hale geldiği ve dolaylı olarak güç üretim hızını azaltıp kas aktivasyonunda gecikmelere neden olduğu şekilde açılklanabilir (32).

Araştırma sonucunda katılımcıların farklı germe egzersizi protokolleri açısından doğrusal koşu $10 \mathrm{~m}, 20 \mathrm{~m}, 30 \mathrm{~m}$ performansları incelendiğinde, anlamlı farklılık saptandı $(\mathrm{p}<0.05)$. Literatürde, Alikhajeh ve ark. (14) yaşları 14-16 arasında olan 20 erkek futbol oyuncusunun seçilen motor performans ölçümlerini farklı germe protokolleri açısından incelemişlerdir. Germe uygulanmayan evre, statik ve dinamik germe egzersizlerinin 20 m zirve süratleri üzerindeki etkisini ölçmüşler, elde edilen bulgulara göre en iyi sonucun dinamik germe protokolünde olduğunu belirlemişlerdir (14). Gelen ve ark. farklı ısınma protokollerinin sürat performansına olan akut etkilerinin karşılaştırmayı amaçlamışlardır. Elli iki kişiden oluşan denek grubu birbirini izlemeyen günlerde üç farklı ısınma protokolünü uygulamıştır. Sonuç olarak sürat koşusu gibi şiddetli güç gereksinen aktiviteler öncesinde dinamik egzersizlerin sporcunun optimal performans sergilemesinde daha uygun olduğu sonucuna varmışlardır (18). Statik germenin doğrusal koşu performansı üzerinde pozitif etki yapmaması, statik germe sonucu kas-tendon ünitesinde meydana gelen değişimlere bağlanmaktadır (33). Ayrıca statik germe ile kas gerimindeki artışın performans değerlerini düşürdüğü söylenebilir. Germenin etkisi ile değișen kas katılığı performans düşüşlerini açıklar niteliktedir. Ayrıca, kasın gerilme süresinin artması ile performans arasında ters bir ilişki olduğu ifade edilebilir.

Araştırma sonucunda, dinamik germe egzersizi protokolünün diğer germe egzersizi protokollerine kıyasla doğrusal koşu performansına pozitif etki edeceği hipotezi doğrulandı. Ancak dikey sıçrama, zirve güç, ortalama güç ve çeviklik performans değerleri açısından bu etki anlamlı bulunmadı. Aktif spor yapan bireylerin performans öncesi germe egzersizi protokolü tercihleri noktasında, bu araștırmanın önemli olduğu düşünülmektedir. Sonuç olarak; özellikle performans odaklı spor yapan bireylerin doğrusal koşu öncesi "DG" uygulamaları yapmalarının performans üzerinde olumlu bir etki göstereceği söylenebilir. Dikey sıçrama gibi aynı zamanda ortalama ve zirve gücün hesaplanabildiği aktivitelerden önce "SG" uygulamalarının yapılması performansı olumsuz yönde etkilediği için önerilmemektedir.

\section{KAYNAKLAR}

1. Herbert RD, Gabriel M. Effects of stretching before and after exercising on muscle soreness and risk of injury: systematic review. BMJ. 2002;325(7362):468-70.

2. Akgün N. Egzersiz Fizyolojisi. 2. Baskl. İzmir: Ege Üniversitesi Matbaası; 1994.

3. Febbraio MA, Carey MF, Snow RJ, et al. Influence of elevated muscle temperature on metabolism during intense, dynamic exercise. Am J Physiol Regul Integr Comp Physiol. 1996;271(5 Pt2):R1251-5.

4. Bishop DJ. Warm up II: performance changes following active warm up and how to structure the warm up. Sports Med. 2003;33(7):483-98.

5. McGowan CJ, Pyne DB, Thompson KG, et al. Evaluating warm-up strategies for elite sprint breaststroke swimming performance. Int J Sports Physiol Perform. 2016;11(7):975-8.

6. Young WB, Behm DG. Should static stretching be used during a warm-up for strength and power activities? J Strength Cond Res. 2002;24(6):33-7.

7. Zakas A, Balaska P, Grammatikopoulou MG, et al. Acute effects of stretching duration on the range of motion of elderly women. J Bodyw Mov Ther. 2005;9(4):270-6.

8. Chaouachi A, Castagna C, Chtara M, et al. Effect of warm-ups involving static or dynamic stretching on agility, sprinting, and jumping performance in trained individuals. J Strength Cond Res. 2010;24(8):2001-11.

9. Cramer JT, Housh TJ, Johnson GO, et al. An acute bout of static stretching does not affect maximal eccentric isokinetic peak torque, the joint angle at peak torque, mean power, electromyography, or mechanomyography. J Orthop Sports Phys Ther. 2007;37(3):130-9. 
10. Robbins JW, Scheuermann BW. Varying amounts of acute static stretching and its effect on vertical jump performance. J Strength Cond Res. 2008;22(3):781-6.

11. Winchester JB, Nelson AG, Landin D, et al. Static stretching impairs sprint performance in collegiate track and field athletes. J Strength Cond Res. 2008;22(1):13-9.

12. Ogura Y, Miyahara Y, Naito H, et al. Duration of static stretching influences muscle force production in hamstring muscles. J Strength Cond Res. 2007;21(3):788-92.

13. Faigenbaum AD, Kang J, McFarland J, et al. Acute effects of different warm-up protocols on anaerobic performance in teenage athletes. Pediatr Exerc Sci. 2006;17(1):64-75.

14. Alikhajeh Y, Rahimi NM, Fazeli H, et al. Differential stretching protocols during warm-up on select performance measures for elite male soccer players. Procedia Soc Behav Sci. 2012;46:1639-43.

15. McMillian DJ, Moore JH, Hatler BS, et al. Dynamic vs. static-stretching warm up: the effect on power and agility performance. J Strength Cond Res. 2006;20(3): 492-9.

16. Holt BW, Lambourne K. The impact of different warmup protocols on vertical jump performance in male collegiate athletes. J Strength Cond Res. 2008;22(1):226-9.

17. Faigenbaum AD, Bellucci $M$, Bernieri A, et al. Acute effects of different warm-up protocols on fitness performance in children. J Strength Cond Res. 2005; 19(2):376-81.

18. Gelen E, Meriç B, Yıldız S. Farklı ısınma protokollerinin sürat performansına akut etkisi. Turkiye Klinikleri J Sports Sci. 2010;2(1):19-25.

19. Pauole K, Madole K, Garhammer J, et al. Reliability and validity of the T-test as a measure of agility, leg power, and leg speed in college-aged men and women. $J$ Strength Cond Res. 2000;14(4):443-50.

20. Johnson DL, Bahamonde R. Power output estimate in university athletes. J Strength Cond Res. 1996;10(3):161-6.

21. Karvonen MJ, Kentala E, Mustala O. The effects of training on heart rate: a longitudinal study. Ann Med Exp Biol Fenn. 1957;35(3):307-15.
22. Alter MJ. Sports Stretch. 2nd edition. Champaign, IL: Human Kinetics Pub;1998.

23. Joggers JR, Swank A, Frost KL, et al. The acute effects of dynamic and ballistic stretching on vertical jump height, force, and power. J Strength Cond Res. 2008;22(6):1844-9.

24. Little T, Williams AG. Effects of differential stretching protocols during warm-ups on high-speed motor capacities in professional soccer players. J Strength Cond Res. 2006;20(1):203-7.

25. Haghshenas R, Taleb-Beydokhti İ, Avandi SM. Acute effect of different warm-up stretch protocols on vertical jump performance in volleyball players. Int. J Sport Studies. 2014;4(8):907-13.

26. Franco BL, Signorelli GR, Trajano GS, et al. Acute effects of three different stretching protocols on the Wingate test performance. J Sports Sci Med. 2012;11(1):1-7.

27. Kendall BJ. The acute effects of static stretching compared to dynamic stretching with and without an active warm up on anaerobic performance. Int J Exerc Sci. 2017;10(1), 53-61.

28. Chatzopoulos D, Galazoulas C, Patikas D, et al. Acute effects of static and dynamic stretching on balance, agility, reaction time and movement time. J Sports Sci Med. 2014;13(2):403-9.

29. Amiri-Khorasani M, Sahebozamani M, Tabrizi KG, et al. Acute effect of different stretching methods on Illinois agility test in soccer players. J Strength Cond Res. 2010;24(10):2698-704.

30. Magnusson SP, Simonsen EB, Aagard P, et al. Biomechanical responses to repeated stretches in human hamstring muscle in vivo. Am J Sports Med. 1996;24(5):622-8.

31. Kokkonen J, Nelson AG, Cornwell A. Acute muscle stretching inhibits maximal strength performance. Res Q Exerc Sport. 1998;69(4):411-5.

32. Kubo K, Kanehisa H, Fukunaga T. Is passive stiffness in human muscles related to the elasticity of tendon structures? Eur J Appl Physiol. 2001;85(3-4):226-32.

33. Schilling BK, Stone MH. Stretching: Acute effects on strength and power performance. Strength Cond J. 2000;22(1):44-7. 